\title{
Lo lezamiano en la conformación de El lobo, el bosque y el hombre nuevo de Senel Paz
}

Luis Alberto Arellano Hernández

El Colegio de San Luis

\section{Resumen}

Este artículo explora la relación intertextual entre Paradiso, de José Lezama Lima, y El lobo, el bosque y el hombre nuevo, de Senel Paz, con la finalidad de demostrar la dependencia formal, intelectual y temática que la pieza de Paz mantiene con la de su antecesor. La novela de Paz se lee como una realización de las ideas "criollas" de Lezama Lima, sobre todo aquellas que están señaladas en $L a$ expresión americana y en los escritos que señalan el método de reflexión histórica en Las eras imaginarias.

Palabras clave: criollismo, Lezama, Senel Paz, intertextualidad, reflexión historiográfica, imaginación americana.

\section{Abstract}

This article explores the intertextual relation between Paradiso, of Jose Lezama Lima, and El lobo, el bosque y el hombre nuevo, of Senel $\mathrm{Paz}$, in order to demonstrate the formal, intellectual and thematic dependence that Paz's piece has with the work of his predecessor. The novel by Paz can be read like a realization of Lezama's "criollas" ideas, especially those that are outlined in La expresion americana and the writings that indicate the method of historical reflection in Las eras imaginarias.

Keywords: Criollismo, Lezama Lima, Senel Paz, Intertextuality, Historiografic reflection, American imagination. 
Yo combino:

el aguacero pega en el lomo de los caballos, la siesta atada a la cola de un caballo, el cañaveral devorando a los caballos, los caballos perdiéndose sigilosamente en la tenebrosa emanación del tabaco, el último gesto de los siboneyes mientras el humo pasa por la horquilla

como la carreta de la muerte, el último ademán de los siboneyes, y cavo esta tierra para encontrar los idolos y hacerme una historia.

Virgilio Piñera

\section{"y habiendo chocolate, había pedido fresa"}

$\mathrm{E}$ hecho de que la versión cinematográfica de El lobo, el bosque y el hombre nuevo (1990), de Senel Paz, sea más ampliamente difundida que la propia nouvelle ha opacado algunos de los alcances de esta pieza; circunscribiendo su impacto a la crítica, explícita o implícita, del régimen comunista de la isla cubana. Los temas que esta crítica reviste tienen que ver con la persecución a los homosexuales que llevó a cabo el gobierno durante la década de los setenta; con la reconciliación entre una versión de alta cultura y el mundo construido por la Revolución y, sobre todo, con los peligros ideológicos que acechaban a los cubanos después de la caída del Muro de Berlín en 1989. Tales son las apreciaciones de, por ejemplo, Enrico María Santíen en su artículo de 1998. Pocos han resaltado los motivos lezamianos de la pieza, sin embargo, el que más se ha acercado ha sido Eloy E. Merino (2004), ya que centra su análisis en los usos del almuerzo que ofrece Diego a David. No obstante, aunque señala la marcada intertextualidad que tiene 
este pasaje con el capítulo siete de Paradiso, su trabajo se enfoca en reproducir los argumentos (variantes más, variantes menos) de Enrico María Santí al hablar del filme Fresa y Chocolate: el almuerzo supone una especie de reconciliación entre el mundo de la alta cultura gay y el régimen revolucionario; también es una especie de puesta en escena que revela un rico pasado lezamiano; por último, es el punto culminante en la educación sentimental de David a cargo de Diego, quien le ha mostrado un mundo prohibido por el gobierno y donde se esconde una veta que no está en el horizonte de posibilidades que ofrece la Revolución.

Es por eso que el interés del presente trabajo se encamina a explorar las posibles relaciones textuales entre Paradiso y la pieza de Senel Paz, aunque también se toma en cuenta la obra ensayística de Lezama Lima. Cabe resaltar que la relación explícita del almuerzo lezamiano que Diego ofrece a David forma parte de un diálogo entre los dos personajes. Es por eso que esta pista, de tan sencilla comprobación, anima al presente trabajo a internarse con mayor profundidad en las claves que permiten esta referencia. No se trata de negar estas lecturas, sin duda presentes y comprobadas por los marcados intentos de conciliación explícita puestos por el autor en boca de sus dos personajes, sino de ampliar los rangos de intertextualidad y aventurar una explicación del porqué esta relación parece vertebrar la enciclopedia y la figuración retórica del relato de Senel Paz. Es innegable, entonces, que el personaje de David sufre una transformación con respecto a su idea de Diego. Es también evidente que Diego da sobradas muestras de inconformidad por lo que parece ser una invisibilidad del mundo gay en el universo de referencia cultural del régimen cubano. No es el hecho de ser gay por el cual pide su lugar, sino que, precisamente, por ser gays se han borrado diversos aportes de autores y con ello se les ha negado el reconocimiento merecido. Así, pues, es pertinente preguntar cómo es que la obra y figura de Lezama Lima sirve de ejemplo 
para esta reconciliación, posible o no, y si es éste el papel —el de ejemplo- que el autor asigna a una obra constantemente referida.

\section{"Tengo más bolsas que un canguro"}

En el marco del relato es claro que los referentes culturales cobran una importancia vital, tanto por su carácter de elementos deseables como por el hecho de ofrecer pistas para la comprensión de la ficción. Por un lado, los títulos de novelas y nombres de autores que Diego blande ante la mirada deseosa de David son una forma de seducción, una manera de plantar una estaca y separar la visión del mundo restringido, ideológica y materialmente, del militante revolucionario con respecto de la apertura de miras y objetos que la militancia (otra militancia) gay ofrece a sus acólitos. Esta seducción abierta basada en las prohibiciones económicas e ideológicas de la Revolución permite deslumbrar y tentar al indeciso David. ${ }^{1}$ Es una estrategia probada, que Diego despliega con aparente descuido y gran simpatía. Esta tensión que se establece al inicio de la narración, pero que recorre las relaciones posibles entre los dos mundos ahí expresados, se resume en la anhelante frase que lanza el narrador (David) ante el ejemplar de La guerra del fin del mundo, de Vargas Llosa, recién editada en España: "Vargas Llosa era un re-

${ }^{1}$ Reinaldo Arenas reflexiona sobre esta seducción en Antes de que anochezca (1992). A pesar de mostrar constantemente un marcado distanciamiento del mundo intelectual cubano, existen pasajes en el texto donde el valor simbólico de la cultura es usada como arma de seducción. Valga un solo ejemplo para mostrar lo dicho: "Recuerdo a un teniente que, al saber que yo hablaba un poco de francés, se empeñó en que yo le enseñara esa lengua en las horas libres. Y las clases comenzaban cuando el teniente decía: 'Vamos a estudiar francés'. Y cogiéndose los testículos con la mano los depositaba sobre la mesa en que yo impartía las clases. Con aquel miembro erecto y aquellos testículos a sólo unas pulgadas de la libreta donde yo le escribía algunas frases en francés, yo prolongaba los estudios durante muchas horas" (155). 
accionario, hablaba mierdas de Cuba y el Socialismo donde quiera que se paraba, pero yo estaba loco por leer su última novela y mírala allí: los maricones todo lo consiguen primero" (Paz, 1991: 12).

Por otra parte, los contenidos de las obras aludidas, ya sea en los libros o en la plástica, la música o la danza, al formar parte del inventario de la cultura mundial en la modernidad, dibujan una suerte de taller formativo que tiene como efecto dos aspectos que es necesario resaltar: en primer lugar, amén de aportar verosimilitud a la fábula, permiten rastrear una especie de biografía intelectual del personaje de Diego y, en segundo lugar, dan cuenta de qué se busca representar en los diversos momentos en donde la irrupción de los referentes culturales explícitos da cuenta de una particular significación para lo narrado.

Así, las referencias a Goytisolo, Martí, Alicia Alonso (bailarina), Ibsen, John Donne, Kavafis, María Malibrán (soprano), María Callas, Teresa Stratas, Renata Tebaldi, Celina Gómez, La Casa de muñecas, El lago de los cisnes, entre otros muchos, forman la pléyade de recursos que el autor dispone para dibujar el sintagma que forma al personaje Diego; el cual será atractivo para David por permitirle el ingreso a una cultura (alta y baja) proscrita por el régimen comunista de la isla, pero también por ser parte del inventario necesario por el cual un artista se forma como tal.

No obstante, el lugar principalísimo en esta constelación de nombres y obras lo ocupa José Lezama Lima y su obra. Sin embargo, no sólo su obra sino también la mención explícita a su método de enseñanza (manifestado en la lectura de libros no literarios para poblar de verosimilitud a los textos incipientes de David) y a su método de seducción da cuenta que el pathos lezamiano estructura como un eje la construcción del relato de Senel Paz:

Un día, una tarde de noviembre, cuando es más bella la luz habanera, pasearemos frente a su casa, en la calle Trocadero. Vendremos de Prado, caminando por la acera opuesta, conversando y 
como despreocupados. Tú llevarás puesto algo azul, color que tan bien te queda, y nos imaginaremos que el Maestro vive, y que en ese momento espía por las persianas. Oye su respiración entrecortada, huele el humo de su tabaco. Dirá: 'Mira a esa loca y su garzón, cómo se esfuerza ella en hacerlo su pupilo, en vez de deslizarle un buen billete de diez pesos en la chaqueta' (Paz, 1991: 39).

Es así que la huella de Lezama es permanente en las marcas textuales que estos referentes, antes explicados, aportan para la comprensión del relato.

\section{"Hay que comenzar por el principio, porque talento tienes"}

Una vez que la "presencia" de Lezama Lima y su obra ha sido puesta en relieve, conviene hacer constar qué tipo de relación guarda el texto de Senel Paz con los del Maestro. En principio, hay que decir que la relación posible de esta configuración es la descrita por Gerard Genette bajo el concepto de trantextualidad, específicamente en su variante de hipertextualidad: "Llamo, pues, hipertexto a todo texto derivado de un texto anterior por transformación simple (diremos en adelante transformación sin más) o por transformación indirecta, diremos imitación" (1989:17). Es claro, incluso para el teórico francés, que esta forma de relación entre textos es el rasgo más distintivo de la literariedad. De algún modo todos los textos literarios guardan una relación de derivación con respecto a otros anteriores. No obstante, aún cuando este rasgo de literariedad sea una forma textual de establecer una tradición, no quiere decir que siempre sea del mismo modo y en la misma medida que la derivación antes señalada. El rasgo que destaca Genette para establecer esta singularidad está sobre todo en el establecimiento de un contrato que asegure esta derivación (por ejemplo, en el título) o en alguna marca textual que oriente en esta dirección. No es, 
por supuesto, necesario que sea explícito, como en un paratexto, sino que puede estar sujeto a la decisión del lector. Dicho de otro modo, y refiriendo al caso que nos ocupa, en un primer momento es evidente (el narrador así lo hace notar) que Paradiso de Lezama Lima funciona como hipotexto para El lobo, el bosque y el hombre nuevo. Por lo tanto, es necesario señalar la distinta procedencia de las marcas textuales que dan cuenta de esta relación. Así, se encuentran las menciones explícitas a la figura y la obra de Lezama Lima; por ejemplo, lo ya seńalado como su método de enseńanza, su método de seducción y sus labores en el régimen comunista (cfr. Paz, 1991: 39). Existen, además, extractos de Paradiso que no están siempre seńalados como cita y que pueden o no tener una función paródica, como en el caso del almuerzo que funciona como clímax de la pieza. Por último, sobresale el sistema de referencias que apunta los intereses intelectuales, políticos y artísticos de Lezama, el cual puede ser rastreado como parte de un modelo de cultura y cubanía, entendiendo esto último como una indagación sobre aquello que configura una comunidad nacional, y que no es tratado de manera explícita en el relato de Paz, así como algunas otras referencias a los diversos textos donde Lezama indagó sobre la configuración de una identidad americana. Aquí, forma parte destacada su idea de metodología para la construcción de una teoría de la imaginación poética.

No es la intención de este trabajo agotar todas las cuestiones aquí perfiladas, sino establecer un estado de la cuestión e indagar, así sea parcialmente, algunos de los motivos más interesantes de la relación entre los dos textos. La función de hipertexto que mantiene El lobo, el bosque y el hombre nuevo con Paradiso pone de manifiesto que la elección, por parte de Lezama, del personaje llamado Diego, tutelar de la educación sentimental sobre David, responde a motivos más profundos que traen a cuenta una relación conflictiva entre el régimen castrista y la intelectualidad gay de la isla. Es, 
además de la intención manifiesta por el narrador, una declaración de principios que encierra un tutelaje conceptual arraigado en las diversas facetas y géneros de la obra lezamiana que se puede anclar en dos conceptos claves de la misma: el criollismo como concreción de lo barroco en América y la manera en que las "Eras imaginarias" configuran esta posibilidad (causalidad determinada por lo incondicionado, diría Lezama).

Es de notar que los tres tipos de marcas textuales aquí señalados son también las maneras en que el adjetivo "lezamiano" toma contenido, merced de los usos dentro del texto de Paz. La manera de configurar este vocablo, que aparece despojado de significación a priori, descansa en la premisa de que el texto de Paz contiene las claves para entender qué se busca fijar al referirse de este modo a la constelación de una obra que tiene tantas entradas para ser analizada.

\section{“Ibsén”}

El conflicto inicial, determinante para revelar la estructura de la pieza como una versión de la educación sentimental e intelectual, es el que vive David ante el despliegue de objetos seńaladamente contrarrevolucionarios cargados por Diego en su primer encuentro en Copelia. Ante su deseo de leer el libro de Vargas Llosa, David opone su conciencia de Joven Brigadista. Es decir, ante el placer de lo prohibido, opone su conciencia revolucionaria. El problema es que los sucedáneos que la conciencia revolucionaria le ofrece para paliar el deseo por lo valioso de la cultura prohibida son simples remedos de cursilería bobalicona encubiertos de fervor patrio. El conflicto que David vive ante Diego, en este primer encuentro, está acentuado porque su experiencia en el ámbito cultural de la Revolución es deplorable. David se declara producto de la Revolución. Es un guajiro, villeño, que puede estudiar en la Universi- 
dad y que debe a la Revolución su ascenso en la escala social. Sin embargo, entre más aprende y conoce mundo, más simple y cursi le parece lo que la Revolución sanciona como pertinente en esa esfera. Por eso, ante el fingido desinterés que muestra por el galanteo de Diego, ataca con lo más selecto de su arsenal y le reduce llamándolo Torvaldo.

Cuatro años atrás, a mi profesora de literatura en el preuniversitario, que no sólo era una profesora de literatura frustrada, sino también una directora de teatro frustrada, le llegó la oportunidad de su vida cuando la escuela no alcanzó el primer lugar en la emulación inter-Becas por falta de trabajo cultural. Fue a ver al director y lo convenció, primero, de que a Rita y a mí nos sobraba talento histriónico, y después, de que ella podía guiarnos con mano segura en Casa de muñecas, una obra que, si bien extranjera, pero ya lo dijo Martí, compañero director, insértese el mundo en nuestra República, estaba libre de ponzoñas ideológicas y figuraba en el programa de estudios revisado por el Ministerio en el verano pasado (Paz, 1991: 19).

Todo el episodio es una caricatura que ilustra la pobreza, la rigidez y, sobre todo, la vocación por el ridículo de una educación cultural que tiene supeditado el contenido y la expresión a los fundamentos ideológicos de la Revolución. La cadena de sucesos y situaciones lamentables culmina con el compañero director, que hace una tarea revolucionaria de la participación de David en la obra. La representación, por supuesto, es un fracaso. No sólo por las premisas que movían a los involucrados (Rita enamorada y muda, el compañero director acorralado por los malos resultados, David respondiendo al llamado revolucionario y la profesora de literatura cumpliendo su sueño) sino a razón del olvido y parálisis de Rita como protagonista de la obra en el momento más dramático de su personaje. Así, David, Torvaldo, debe llevar el clímax de la obra en 
hombros y recitar ambos personajes como si fuera un largo monólogo, sin sentido y poco verosímil, pero convencido de que está haciendo lo correcto. El final de la puesta en escena es apoteósico, digno de la peor pesadilla de teatro estudiantil: suena El lago de los cisnes, mientras se proyectan fotos de milicianas y poemas de Juana de Ibarbourou. Cae el telón.

Así, toda la secuencia está configurada para poner de relieve el contraste entre la pobreza de oportunidades que tiene David dentro de la Revolución y los placeres que le esperan al cruzar la línea que separa lo legal de lo ilegal, lo correcto de lo perverso, lo heterosexual de lo gay. "Yo, uno, soy maricón. Dos: soy religioso. Tres: he tenido problemas con el sistema; ellos piensan que no hay lugar para mí en este país, pero de eso, nada; yo nací aquí; soy, antes que todo, patriota y lezamiano, y de aquí no me voy ni aunque me peguen candela por el culo" (Paz, 1991: 19).

Los rasgos que dibujan a Diego son atractivos para David porque dejan entrever una enciclopedia que no está a su alcance por los medios oficiales. Referentes que sólo se despliegan una vez que es convencido por Diego para acompañarlo a su casa. Sin embargo, a pesar de los intentos de seducción, el pacto que se establece entre ellos es el de un pupilaje que pondrá en concordancia la Tarea con el Maestro:

David, vuelve. Creo que hoy no me he sabido explicar. Quizás te he parecido superfluo. Como todo el que habla mucho, hablo boberías. Es porque soy nervioso, pero me he sentido distinto conversando contigo. Conversar es importante, dialogar mucho más. No tengas miedo de volver, por favor. Sé respetar y medirme con cualquier persona y puedo ayudarte muchísimo, prestarte libros, conseguirte entradas para el ballet, soy amiguísimo de Alicia Alonso y me encantaría presentarte un día en casa de la Loynaz, a las cinco de la tarde, un privilegio que sólo yo puedo proporcionarte. $\mathrm{Y}$ quisiera obsequiarte con un almuerzo lezamiano, algo que no 
ofrezco a todo el mundo. Sé que la bondad de los maricones es de doble filo, como apunta el propio Lezama en alguna parte de su obra, pero no en este caso (Paz, 1991: 28-29). ${ }^{2}$

La incorporación reiterada de Lezama como adjetivo para demostrar una filiación plantea varias preguntas. ¿Qué es lo lezamiano de la vida de Diego? ¿De la vida en la Habana? Sin duda, por la forma en que se utiliza en estos dos ejemplos, tiene varias acepciones o incluye varios aspectos distintivos: por un lado, es un rasgo que pinta una forma de entender la cubanía, un rasgo de identidad que abarca una serie de comportamientos y filiaciones, no sólo con Lezama y su obra, sino con los temas y los tratamientos que él incorpora (el principal rasgo que se quiere destacar guarda relación con lo barroco en Lezama); por otro lado, es claro que el adjetivo también incluye, en su forma más reducida, pasajes de la obra del Maestro. Es decir, un estilo y también una referencia a tal o cual imagen proveniente de un texto específico. Así, la configuración de lo lezamiano, en principio, nace por destacar una filiación con la obra del escritor cubano, pero también por dibujar un mapa, una constelación de temas, objetos y, sobre todo, un estilo fincado en lo Barroco como modelo de expresión.

\section{"El traje me lo prestó Bruno"}

Que el pasaje del almuerzo lezamiano está construido a partir de Paradiso es algo que el mismo narrador pone en boca de los personajes; que éste es el momento donde la disciplina intelectual a la que es sometido David llega a su punto más alto y, por tanto,

${ }^{2}$ Aquí vale la pena señalar otro rasgo de hipertextualidad, no con Lezama, sino con Reinaldo Arenas: la clasificación de la comunidad gay. El listado de confiabilidad que se puede dar al homosexual frente al dictado de su deseo $(C f$. Arenas, 1992: 103ss; Paz, 1991: 33-37). 
es el punto climático de la narración, ha sido ya estudiado en los estudios mencionados. No obstante, la manera en que estas dos situaciones se articulan desde los dos textos, Paradiso y El lobo, el bosque y el hombre nuevo, son el motivo de esta indagación.

Hay que tener en cuenta que el capítulo siete, donde sucede la cena lezamiana (transfigurada en almuerzo en Paz), es de singular importancia para la historia de Paradiso porque es el apartado medular de la novela que consta de catorce episodios y, también, porque marca una división central para el desarrollo de la historia de José Cemí, protagonista principal. Por lo tanto, la novela puede ser leída como la formación espiritual e intelectual de José Cemí y su desarrollo como poeta hacia el final de la historia. Antes de este capítulo, sin embargo, Cemí es un niño envuelto en el ambiente familiar de su abuela, su madre, sus hermanos y su tío (dado que es huérfano de padre); después, estará envuelto en sus años de formación escolar, el bachillerato y la universidad.

En el capítulo siete, su participación es de simple espectador, mientras que en el resto de la novela toma el papel protagónico. Este capítulo está centrado en dos figuras: dońa Augusta, la abuela, y el tío Alberto, su hijo varón. La familia de Cemí, acaudalada e importante en la ciudad, es gobernada con mano dura por la abuela Augusta. El tío Alberto es un escándalo para la familia debido a su indefinición laboral y su resistencia a "sentar cabeza" en el mundo criollo de la narración. El capítulo comienza con la irrupción del tío en la casa familiar buscando que la abuela, su madre Augusta, le proporcione dinero para continuar la borrachera. Ella se lo entrega, pero le lanza un discurso notable de reproche y desprecio. El tío avergonzado vuelve a la calle. Se anuncia la llegada de la tía, hermana de la madre de Cemí e hija de Augusta, desde otra ciudad y se prepara una cena para recibir tanto a ella como a su familia. El marido de la tía, el doctor Demetrio Santurce, ha sido compañero de estudios de Alberto y ahora es médico de la 
familia. Antes de su llegada, Cemí ha descubierto, por boca de Demetrio, que su tío Alberto es poeta, para muestra el doctor le lee una carta que recibió de él mientras compartían residencia profesional. Cemí escucha arrobado por revelársele una coincidencia espiritual con el tío Alberto. El texto es muestra de la delicadeza e ingenio propios de Lezama. Sin embargo, el tío Alberto representa lo opuesto al mundo femenino donde ha sido criado y desde donde observa al mundo. El tío Alberto representa la sordidez y la violencia del mundo masculino. Saber que el tío es poeta le da a Cemí la carta de naturalización necesaria para formar parte de los varones de la familia.

A la llegada de la tía y de Santurce, más allá de las ocho de la noche, doña Augusta llama a la mesa:

Doña Augusta se había preocupado de que la comida ofrecida tuviese de día excepcional, pero sin perder la sencillez familiar. La calidad excepcional se brindaba en el mantel de encaje, en la vajilla de un redondel verde que seguía el contorno de todas las piezas, limitado el círculo verde por los filetes dorados. [...] $\mathrm{El}$ color crema del mantel, sobre el que destellaba la perfección del esmalte blanco de la vajilla, con sus contornos de verde quemado, conseguía el efecto tonal de una hoja reposada en la mitad del cuerpo menguante lunar (Lezama, 1968: 164).

En la pieza de Paz se lee: "La calidad excepcional del almuerzo, como decía el propio Lezama en Paradiso, según supe después, se brindaba en el mantel de encajes, ni blanco ni rojo, sino color crema, sobre el que destellaba la perfección de la vajilla con sus contornos de verde quemado" (1991: 41).

En ambos casos, la descripción corre inicialmente a cuenta de los narradores, heterodiegético en Lezama, intradiegético en Paz. No obstante, conforme avanza la narración en el desarrollo de la comida, los personajes se van apropiando del recurso, e incluso 
Diego, a manera de Augusta, va reproduciendo textualmente los diálogos y emisiones de juicios que se van sucediendo tanto en el narrador como en los personajes de Lezama:

Doña Augusta destapó la sopera, donde humeaba una cuajada sopa de plátanos. — Los he querido rejuvenecer a todos — dijotransportándolos a la primera nińez, y para eso le he ańadido a la sopa un poco de tapioca. Se sentirán nińos y comenzarán a elogiarla, como si la descubrieran por primera vez. He puesto a sobrenadar unas rositas de maíz, pues hay tantas cosas que nos gustaron de niño y que sin embargo no volveremos a disfrutar. Pero no se intranquilicen, no es la llamada sopa del oeste, pues algunos gourmets, en cuanto ven el maíz, creen ver ya las carretas de las emigraciones hacia el oeste, a principios del siglo pasado, en la pradera de los indios sioux —al decir eso, miró hacia la mesa de los garzones, pues intencionadamente había terminado su párrafo para apreciar cómo se polarizaba la atención de sus nietos (1968: 164-165).

El narrador (David), en la pieza de Paz:

Diego destapó la sopera, donde humeaba una cuajada sopa de plátanos. "Te he querido rejuvenecer", dijo con una sonrisa misteriosa, "transportándote a la primera niñez, y para eso le he añadido a la sopa un poco de tapioca...” “¿Eso qué es?” "Yuca, niño, no me interrumpas. He puesto a sobrenadar unas rositas de maíz, pues hay tantas cosas que nos gustaron de niño y que sin embargo nunca volvemos a disfrutar. Pero no te intranquilices, no es la llamada sopa del oeste, pues algunos gourmets, en cuanto ven el maíz, creen ver ya las carretas de los pioneros rumbo a la California, en la pradera de los indios sioux. Y aquí debo mirar hacia la meza de los garzones" (1991: 41-42).

Es capital señalar que aquí comienzan a aparecer sintagmas que se vuelven incomprensibles o meramente alusiones de carácter or- 
namental si no se tiene presente la referencia de lo sucedido en el capítulo siete de Paradiso. Tal es el caso de esa última frase, que en boca de doña Augusta es un gesto de provocación a los niños que están en otra mesa distinta a la de los adultos, y el siguiente enunciado del narrador que explica el gesto. En el caso de Diego, la referencia a los sioux y la enunciación final que refiere a la mesa de los garzones es sólo un gesto en apariencia vacío, pero que asegura la referencia a la obra de Lezama y añade una dimensión de ritual, de sacrificio, al almuerzo con David. Estas marcas que señalan la relación de hipertexto que guarda la pieza de Paz con la de Lezama no pueden ser leídas sólo como paródicas, sino como una suerte de iniciación, donde la representación del signo lezamiano se ha trastocado en una performance. Esto, como se verá, es de capital importancia por la dimensión que guarda la imaginación poética como método en la obra de Lezama.

Después de la ceremoniosa sopa y la descripción de Augusta, Santurce (el pedante yerno) aborda la posibilidad de un infarto por la cantidad y la calidad de la gastronomía desplegada. El señalamiento lleva a Alberto a discurrir sobre los secretos del corazón en tanto órgano. En un toma y daca, donde Santurce trata de zanjar la discusión, merced su conocimiento médico, la última frase que se emite hace mención al corazón del canario y la velocidad de sus latidos.

- Troquemos - dijo dońa Augusta para terminar la ociosa discusión —el canario centella por el langostino remolón- Hizo su entrada el segundo plato en un pulverizado soufflé de mariscos, ornado en la superficie por una cuadrilla de langostinos, dispuestos en coro, unidos por parejas, distribuyendo sus pinzas el humo brotante de la masa apretada como un coral blanco. [...] Formaba parte también del soufflé, el pescado llamado emperador, que doña Augusta sólo usaba en el cansancio del pargo, cuya masa se había extraído primero por círculos y después por hebras; lan- 
gostas que mostraban el asombro cárdeno con que sus carapachos habían recibido la interrogación de la linterna al quemarle los ojos saltones (Lezama, 1968: 196).

En Paz, Diego realiza, con pequeñas variantes, el recitativo de dońa Augusta. Desde el verbo inicial, trocar, el discurso pierde sentido sin la referencia textual a Paradiso. En la conversación y en el almuerzo con David no hay ningún canario, ni ninguna ave implicada; las especificaciones sobre los peces y mariscos utilizados y el por qué, que el narrador utiliza para demostrar la maestría del doble arte de doña Augusta (gastronómico y verbal), son rasgos que demuestran culpabilidad, por el origen de los productos, escasos ya en ese inicio del "periodo especial" que siguió al derrumbe del bloque socialista en Europa. No puede ser sino por la forma en que el texto de Paz retoma los elementos del texto lezamiano que esta diferencia cobra sentido.

El momento cumbre de la cena-almuerzo, anunciado por Diego, está dado por la ensalada. Una remolacha que Alberto trata de llevar a su plato, merced de su preparación, se parte y mancha el mantel de encaje. En dos ocasiones más trata de llevarla a sí, pero dos veces más deja su marcha borgoña sobre el mantel. Se han formado tres manchas, y juguetón, Alberto toma los carapachos de las langostas y langostinos y hace que cerquen los rosetones dejados por la remolacha. A Diego le sucede la misma calamidad y de igual manera realiza el acomodo, divertido y celebratorio, de los caparazones alrededor de las manchas. En la obra de Lezama, una vez realizada la disposición de los caparazones alrededor de las manchas, el narrador enuncia: "Pero esas tres manchas le dieron de verdad el relieve de esplendor a la comida. En la luz, en la paciencia del artesanado, en los presagios, en la manera como los hilos fijaron la sangre vegetal, las tres manchas abrieron como una sombría expectación” (196). 
Es Diego quien toma la estafeta del narrador y recita los versos finales de la enunciación. En ambos casos, este apresurado final para la cena-almuerzo es un presagio de la tormenta por venir. La última referencia explícita a Paradiso es el frutero que Baldovina lleva a la mesa, pero que en el caso de Paz Diego deba acercar. Un solo detalle final: en ambas comidas, los protagonistas deben terminar hablando de traidores: en el caso de Paradiso, la charla entre Alberto y Santurce corre hacia la figura de Antonio Pérez, el secretario asesino, de la corte de Felipe II; en el caso de El lobo, el bosque y el hombre nuevo, la mención es llevada a la figura de Juan Clemente Zenea, poeta, fuerte opositor a la corona española en el siglo XIX y anglófilo. La figura de Zenea pasa a la historia como un precursor de Martí y uno de los comentaristas más certeros y entusiastas de la guerra hispano-americana del 98. Aquí hay una clave importante a resaltar que conecta el tutelaje de la obra de Lezama con el relato de Paz: la posible traición de Zenea lo es sólo ante un público hispanófilo, ante un criollismo que tiene vivo el recuerdo de Antonio Pérez y su participación en la muerte de Juan de Escobedo, secretario de Juan de Austria, hermano de Felipe II. Sólo si se mira la participación de Zenea en la independencia de Cuba desde el lado español se entiende el cargo de traición que se le imputa. Es elocuente la manera en que Diego se refiere a este personaje: "Después nos queda el café, que tomaremos en el balcón mientras te recito poemas de Zenea, el vilipendiado" (Paz, 1991: 44).

Resta aclarar el sentido del recitado por el narrador y por Diego sobre las manchas en el mantel. En ambos capítulos este jugueteo macabro sobre las manchas en el mantel se vuelve un presagio de la desventura. Al final de la cena, debido a que doña Augusta ha sustraído los licores para evitar disputas, Santurce sale con Alberto a tomar un trago en un bar de la ciudad. En ese lugar le comunica que doña Augusta presenta un carcinoma en el seno izquierdo, 
muy avanzado e inoperable. Esta confidencia, que trastoca toda la constelación familiar de los Olaya, se ve interrumpida por la figura entre ridícula y tenebrosa de un charro mexicano borracho, que tratando de cantar para los parroquianos se enreda en una disputa con Alberto. Ambos terminan en la cárcel, después de recitarse animadas coplas, ${ }^{3}$ en una especie de topada o desafío de ingenio, que los llevó a los golpes. Después de pasar unas horas en la comisaría, son liberados y la antigua disputa se vuelve en franca amistad. Al salir, van a dar serenata, sin embargo, con el alba despuntando, Alberto muere desnucado en un accidente automovilístico.

En el caso de Paz, Diego se siente abrumado por la culpa y despide a David apresurado. La disputa interna de David, actualizada por los productos prohibidos usados en el almuerzo, se ve acicateada por la conducta errática de Diego. Poco después descubre que Diego sale rumbo al exilio. Tanto José Cemí como David se ven despojados de sus recién adquiridos modelos. En el capítulo ocho de Paradiso, Cemí comienza una nueva vida volcada hacia el exterior de la casa familiar donde encuentra otras figuras tutelares. David trata de conservar a Diego y animarlo a quedarse en la isla. Esa nueva orfandad, ahora intelectual y espiritual, es la tragedia que se anuncia con las manchas de remolachas y a la que los versos ya enunciados sirven de oráculo.

\section{“¿qué hago yo con un ladrillo en la mano?”}

De las posibilidades de significación enunciadas arriba, que el término "lezamiano" atisba en relación con el texto de Paz, la tercera (las ideas sobre la Historia, la poesía y las "Eras imaginarias", que se desprende de los ensayos de Lezama Lima) se presenta como la

${ }^{3}$ Por ejemplo, esta cuarteta donde aparece la figura de Tomás de Aquino: "Dadme grave la pluma/ del santo gordo de Aquino,/ para en la resta y la suma/ entonarme a lo divino" (Lezama, 1968: 201). 
que más dificultades ofrece al lector, ya que la escasa circulación y recepción de estos materiales han hecho que sean poco conocidos y peor leídos. En primer lugar, habría que aclarar que cuando se hace referencia a las ideas de Lezama sobre estos tópicos se alude a un corpus articulado e inserto en una discusión compleja, que puede verse en las distintas temáticas tocadas por él en el ensayo. En segundo lugar, con menor seguridad y más tanteo, se puede hacer un rastreo en los escritos de poesía y de narrativa donde estas ideas toman forma y dan cuenta de una solución estética. Sin embargo, el problema parece ser el mismo: ¡a qué se hace referencia cuando se habla de las ideas sobre Historia, poesía y las "Eras imaginarias" en Lezama Lima? Baste aclarar que no se pretende hacer una exhaustiva indagación de los temas, puesto que Lezama es un autor de profundísimos tratamientos y con una abundancia de recursos y referentes que hacen muy complejo el mapeo de una biografía intelectual o, al menos, de un seguimiento puntual de un concepto. Por lo tanto, la intención de este apartado es ofrecer un pequeño resumen de algunas de las cuestiones más recurrentes tratadas por Lezama, y llevar esta recurrencia a la configuración de una red que ayude a presentar como viable su lectura como hipertexto en Senel Paz, donde sirve como una estrategia de filiación y actualización del propio Lezama.

Así, sobresale de su aparato de indagación conceptual la noción de "Eras imaginarias". Con esta denominación Lezama opone, dicho de manera muy sucinta (lo que siempre es un riesgo en este autor), a la cadena de causalidades que conforman la cosmovisión positiva hegeliana ${ }^{4}$ (pero no solamente) un sistema que parte de la indeterminación, pero que no se agota ahí. Es decir, por "Eras imaginarias" Lezama va a entender la manera en que lo indeterminado

${ }^{4}$ Irlemar Chiampi desarrolla la idea de oposición a Hegel en el prólogo titulado "La Historia tejida por la Imagen", con el cual abre su edición de La Expresión americana (Lezama, 1993: 9). 
de un fenómeno logra impactar y volverse determinación. Si en todo fenómeno existen en potencia una gran cantidad de posibilidades, sólo a posteriori nos parece que la efectiva es necesariamente causal. Lezama coloca el acento en el momento previo a que esta causalidad, sólo aparente, tome forma. Si antes, en potencia, todo se encuentra en una misma condición de posibilidad, entonces la posibilidad que se descarta por la forma que toma un evento no desaparece necesariamente, sino que es parte de las posibilidades de forma que tomará en lo sucesivo un fenómeno. Este modo de aparición, irrupción, de lo indeterminado en lo causal será el punto del que parte la imaginación poética, por medio de la palabra, para desplegar todas sus posibilidades. Si el mundo positivo lleva a elegir una forma en detrimento de las otras, la imaginación poética, y sólo ella, permite la convivencia de las posibilidades de la forma en un mismo estatuto de la materia, en este caso, verbal y significativo: "El agrupamiento de las variaciones inconexas, donde la causalidad se libera de la igual distribución de la potencia, nace de un margen espacial que se destrenza como condicionante" (Lezama, 1993: 373).

En otras palabras, y aplicado a la Historia, el fenómeno puede ser pensado por medio de la imaginación poética de un modo amplio e indeterminado, en contrapunto a las posibilidades unívocas de la forma en el esquema causal. Los hechos pueden ser más una superposición de sucesos que una cadena determinista y unidireccional. Así las cosas, las "Eras imaginarias" son las formas posibles de representación en una determinada época de la humanidad. En contrapunto a las Eras geológicas o a las Eras históricas, Lezama propone las Eras imaginarias. No quiere decir con esto que las "Eras" correspondan a un determinado periodo de tiempo de una manera concatenante ni que a cada civilización corresponda una "Era", el problema es mucho más amplio, a fuer de la indeterminación que está en el centro del modelo. Sin duda, estas re- 
presentaciones, estas expresiones se pueden repetir o pueden tener versiones a lo largo de la Historia, pero no son nunca únicas, ni siquiera son dominantes, sino que están siempre en un dinámico juego de espejos donde una representación llama a otra o la refiere.

Los textos en los que Lezama analiza este programa son varios, pero destaca La expresión americana por su carácter de conferencias y por limitar el debate a la configuración de una identidad. La expresión americana es la aportación, tardía, de Lezama a la discusión que desde el siglo XIX va tomando cuerpo en los países latinoamericanos sobre la indagación de la singularidad, tanto de lo nacional como de lo regional. Lezama va a colocar en el centro de la singularidad a lo Barroco, pero va a exponer su método de configuración de la Historia. "Las eras imaginarias" toman forma aquí en situaciones específicas.

En contraparte a lo hasta aquí dicho, debo aclarar que en el caso de La expresión americana esta superposición de representaciones se expresa en figuras que son recurrentes. En el centro de toda la fabulación está El señor Barroco, pero también aparece El criollo. Es en este apartado, el de la expresión criolla, en el cual Lezama coloca la figura de la poesía popular como el rasgo que distingue al americano. Sin embargo, al mismo tiempo, apunta que la poesía popular renueva las potencias de la poesía en general; por lo tanto, es en el territorio americano donde se lleva a cabo la expresión barroca verdadera. La posibilidad del barroco sólo tuvo su máxima expresión en el territorio americano a merced de la apropiación (casi antropofágica) ${ }^{5}$ que el escritor y su imaginación ejercieron con los autores peninsulares:

La espuma del tuétano quevediano y el oro principal de Góngora, se amigaban bien por tierras nuestras, porque mientras en Espańa

\footnotetext{
${ }^{5}$ No es gratuita, como señala Irlemar Chiampi, la cercanía de Lezama, como pensador, con la poética de Oswald de Andrade (Cf. Lezama Lima, 1993: 24).
} 
las dos gárgolas mayores venían recias de la Tradición humanista, en América gastaban como un tejido pinturero, avispón del domingo que después precisamos aumentado en la alabanza principal. [...] Pero por lo americano, el estoicismo quevediano y el destello gongorino tienen soterramiento popular. Engendran un criollo de excelente resistencia para lo ético y una punta fina para el habla y la distinción de donde viene la independencia (Lezama, 1993: 137).

La imagen del hombre americano que Lezama dibuja no es un hombre que se inserta pasivamente en la Historia. Del pasaje anterior, por lo que se lee, se desprende que es la imaginación poética la que posibilita la revuelta independentista del siglo XIX. Es la inversión de los modelos de representación clásicos, donde la Representación es posterior a la Verdad. En el caso de Lezama este orden se invierte: es la Verdad lo que es producto de la Representación. "Desprovisto de la solemnidad interpretativa de los ideólogos del americanismo y sin optimismo enajenante, Lezama pinta su americano como una suerte de Calibán: irreverente, corrosivo, rebelde y devorador" (Lezama, 1993: 24). Parece notable, entonces, que Paz elija esta especie de ritual de actualización para ejemplificar con la propia obra de Lezama un modelo de cultura criolla que es contrapunto y rebelión a las determinaciones históricas.

Bajo la idea de las "Eras imaginarias" es que el adjetivo lezamiano adquiere su significación: no sólo es el modo de referir lo contenido en la obra del Maestro, tampoco se agota en la definición de un estilo; es también una forma que admite la superposición de distintas posibilidades y que puede rastrearse en lo Barroco: "Ese combate entre la causalidad y lo incondicionado ofrece un signo, rinde un testimonio: el poema. Sigamos con un rasguño una sentencia de Pitágoras: 'Existe un triple verbo. Hay la palabra simple, la palabra jeroglífica y la palabra simbólica. Es decir, el verbo que expresa, el verbo que oculta y el verbo que significa”' (Lezama, 1970: 379). 


\section{"me llaman La Loca Roja”}

La relación que establece El lobo, el bosque y el hombre nuevo con la obra de Lezama Lima se expresa en la hipertextualidad aquí consignada, en la figura de Lezama como personaje dentro del relato y, también, en la configuración de un adjetivo que expresa la referencialidad al Maestro. Los contenidos que conforman esta red significante bajo el amparo de lo lezamiano permiten establecer tres grandes categorías: en primer lugar, se trata de la referencia enciclopédica a la obra y los temas de Lezama; en segundo lugar, se puede entender este vocablo como la apropiación de un estilo, bajo el amparo de lo Barroco o como se ha designado en el ámbito de lo poético: lo Neobarroco (Echevarren, 1991: 9); en tercer lugar, al poner en operación una premisa metodológica propia del pensamiento de Lezama, donde la forma toma para sí las posibilidades de lo Histórico de una manera no causal. Lo interesante de esta última categoría es que en oposición al materialismo histórico, método único de lectura de la realidad, propio del régimen comunista, El lobo, el bosque y el hombre nuevo presenta una historicidad que es simultánea y que se aleja de la misión unívoca de la Revolución. Como una forma de presentar lo que la cultura criolla que Lezama resume, la lectura de la representación, no contradictoria a las características con las que Diego se adscribe, logra dar a la imaginación poética una presencia efectiva. La imagen final del relato alude a la posibilidad efectiva de todas las posibilidades formales:

Y cuando estuve en la calle, una fila de pioneros me cortó el paso. Lucían los uniformes como acabados de planchar y llevaban ramos de flores en la mano; y aunque un pionero con flores desde hace rato era un gastado símbolo del futuro, inseparable de las consignas que nos alientan a luchar por un mundo mejor, me gustaron, tal vez por eso mismo, y me quedé mirando a uno, que al darse cuenta me sacó la lengua (Paz, 1991: 59). 


\section{Fuentes}

Arenas, Reinaldo, 1992, Antes de que anochezca, México, Tusquets.

Echevarren, Roberto, 1991, Transplatinos, Muestra de poesía Rioplatense, México, El Tucán de Virginia.

Genette, Gerard, 1989, Palimpsestos. La literatura en segundo grado, Madrid, Taurus.

Lezama Lima, José, 1993, La expresión americana, México, FCE. , 1968, Paradiso, México, Era.

Merino, Eloy E., 2004, "Los usos del almuerzo lezamiano en $E l$ lobo, el bosque y el hombre nuevo, de Senel Paz", Chasqui, vol. 33, núm. 1, mayo, pp. 42- 55.

Paz, Senel, 1991, El lobo, el bosque y el hombre nuevo, México, Era.

Piñera, Virgilio, 1994, Poesía y Crítica, México, Conaculta.

Pińeyro, Enrique, 1901, Vida y escritos de Juan Clemente Zenea, París, Garnier Hermanos.

Santí, Enrico María, 1998, “Fresa y Chocolate’: The rethoric of cuban reconciliation”, $M L N$, Hispanic Issue, vol. 113, núm. 2, (Marzo), pp. 407- 425.

(Artículo recibido el 13 de febrero de 2014; aceptado el 20 de junio de 2014) 